\title{
Research on Technical Management of Mechanical and Electrical Equipment Installation and Construction in Municipal Engineering
}

\author{
Wanting Yang* \\ Hengxu Mechanical and Electrical Co., Ltd. E-mail: wanting@163.com
}

\begin{abstract}
In the construction of municipal engineering, attention should be paid to the installation of mechanical and electrical equipment and active application of integrated mechanical and electrical equipment. Based on this, this article briefly expounds the technical characteristics of installation and construction of mechanical and electrical equipment in municipal engineering, and puts forward the technical management points for it. In addition, it puts forward the application of mechanical and electrical integration, aiming at discussing the technical application points
\end{abstract} from the perspective of management, thus providing reference for engineering installation and construction.

Keywords: Municipal Engineering; Mechanical and Electrical Equipment; Mechanical and Electrical Integration

\section{Introduction}

The construction of municipal engineering requires all kinds of mechanical and electrical equipment to play an auxiliary or supporting role in the operation. If the installation technology of municipal engineering mechanical and electrical equipment is not well grasped, a more scientific management of the application of installation and construction technology can not be implemented, which will inevitably affect the progress and quality of municipal engineering projects. To this end, it is necessary to strengthen the installation and construction technology of mechanical and electrical equipment in municipal engineering and promote the scientific management of technology.

\section{Technical characteristics of installation and construction of mechanical and electrical equipment in municipal engineering}

The mechanical and electrical equipment involved in the construction of conventional municipal engineering projects mainly include water supply and drainage system, power supply and transmission system, monitoring system, lighting system, and ventilation system. The installation and construction features are presented in the following aspects. No matter which kind of mechanical and electrical equipment in municipal engineering is, the installation will attract cooperation from many engineering systems, such as mechanical system engineering, civil engineering system engineering, power transmission and transformation system engineering, and communication monitoring system engineering. Different systems need cooperation and orderly operation to ensure the installation quality of mechanical and electrical equipment. The application of mechanical and electrical equipment in municipal engineering will have a positive impact on the production and life of urban residents. Therefore, the requirements of reliability, stability, safety and convenience of urban residents are accumulating in terms

\footnotetext{
Copyright (C) 2020 Wanting Yang

doi: 10.18282/fme.v2i2.1080

This is an open-access article distributed under the terms of the Creative Commons Attribution Non-Commercial License

(http://creativecommons.org/licenses/by-nc/4.0/), which permits unrestricted non-commercial use, distribution, and reproduction in any medium, provided the original work is properly cited.
} 
of installation and construction efficiency. Driven by these strict requirements, more advanced technologies are often introduced into the installation and construction of mechanical and electrical equipment in municipal engineering.

\section{The technology management points of installation and construction of mechanical and electrical equipment in municipal engineering}

\subsection{Pay attention to equipment supervision}

Technical instructions or construction instructions for the installation of mechanical and electrical equipment in municipal engineering should be stored in time with the help of computers. The contents of the data can be updated in real time according to the installation progress, thus forming an important reference for equipment supervision. The construction and installation party of mechanical and electrical equipment should appropriately increase the investment in equipment supervision, ensure that the informatization level is up to standard, and ensure that the required construction personnel can match the needs of actual posts. Attention should be paid to the supervision of scientific process. First of all, the distribution scheme of mechanical and electrical equipment should be prepared, especially the distribution plan for line and equipment maintenance should be made clear. The distribution scheme should be trained for construction personnel in time so that no mistakes can be made in construction practice. Secondly, a monitoring communication network is set up on the installation and construction site of mechanical and electrical equipment, and the video remote monitoring probe is used as the network node, so as to grasp the construction status in time and give an accurate alarm to the anomalies in remote video monitoring. With the present rapid development of science and technology, various advanced mechanical and electrical installation technologies are also applied in the field of implementation engineering. Enterprises should strengthen the technical level of mechanical and electrical installers in the company, carry out a series of installation technical training through mechanical and electrical installers. They should hire external mechanical and electrical installation management experts to train employees about advanced mechanical and electrical installation work knowledge. Companies shall also set up an internal training platform and a multimedia information management platform, so that employees can learn installation skills and knowledge independently on the platform. Then a good learning atmosphere for employees can be created within the enterprise. At the same time, installers actively carry out engineering communication with employees of various departments to discuss technical problems and relevant knowledge. In addition, the company should strengthen supervision over the process of mechanical and electrical installation, ensure the quality of mechanical and electrical equipment installation, and establish a quality management system to promote the comprehensive level of mechanical and electrical equipment installation.

\subsection{Promote quality management}

The installation of mechanical and electrical equipment in municipal engineering has the complexity of multi-system, so design planning should be made in advance in different links. On the basis of determining scientific installation and construction technology, project quality standardization should be actively strengthened. According to the requirements of standardization, professional, skilled and experienced personnel with high operating level should participate in the installation and construction of different links. The staff with management responsibilities on site should strengthen the awareness of quality management, strengthen the mobilization of resources such as people, machines and materials, effectively reduce the construction loss, reduce unnecessary costs, protect the environment as much as possible, and comprehensively promote the quality of mechanical and electrical equipment installation and construction. At the installation site of mechanical and electrical equipment, the administrators of enterprises need to strengthen the supervision of procurement, transportation and construction operation of mechanical and electrical equipment. The quality department of the company needs to strengthen cooperation with the purchasing department. When purchasing mechanical and electrical equipment, the purchasing personnel and material quality inspectors go to the supplier's enterprise to check the 
production status of the equipment. In combination with the technical standards formulated by the company, the company should strengthen the inspection of products and prevent the purchase of inferior lubricating oil. Company supervisors need to go to the front-line of mechanical and electrical installation site to check the equipment and materials used by construction personnel. Enterprises apply the method of total quality management by establishing internal quality management system, and provide sufficient quality inspectors to scientifically supervise and inspect the mechanical and electrical equipment and materials purchased. For mechanical and electrical products that do not meet the technical standards of the company, it is necessary to inform suppliers to replace equipment or return goods in time. Only the high-quality mechanical and electrical equipment purchased by the company can ensure the efficiency and quality of the whole mechanical and electrical installation process and provide users with high-quality building service. At the same time, efficient and high-quality mechanical and electrical installation services can also improve the company's market share, reputation and credibility, and realize the steady development and operation of the company. When purchasing mechanical and electrical equipment, enterprises should not only consider the equipment price, but also pay more attention to the comprehensive performance and quality of mechanical and electrical equipment, so as to ensure the quality and choose the mechanical and electrical equipment with high quality and low price.

\subsection{Standardize project acceptance}

After the mechanical and electrical equipment installation in each area or stage of the municipal engineering is completed, it shall be put into the project acceptance link in time. The acceptance shall be guided strictly according to the acceptance standards of the state and industry, and equipment testing shall be carried out according to various scientific indexes and parameters to verify the operation conditions of mechanical and electrical equipment. Personnel responsible for supervision and management, such as on-site supervision, shall check the connection contact of bolts, nuts, joints, etc. when the equipment is opened, and check whether the indicator light is abnormal after the equipment runs.
If the display is abnormal, it shall be promptly checked for rectification. After passing the acceptance, the construction party shall arrange the installation and construction related drawings and acceptance data and submit them to the project operator, so as to be helpful for future transportation and management.

The most prominent advantage of the application of mechanical and electrical technology in municipal engineering is the self-inspection and maintenance of related mechanical equipment. Through mechanical and electrical technology, relevant departments and personnel can grasp the operation and use of mechanical equipment in real time, thus realizing the scientific management of mechanical equipment. In the application of mechanical and electrical technology, due to the perfection of functions of electronic control system, the existence of the electronic system can realize good management and control of corresponding mechanical and electrical equipment. For example, dynamic and real-time monitoring of other engines, transmission systems and hydraulic systems is realized. When the relevant equipment parameters are abnormal, the system will automatically carry out relevant self-detection and problem feedback, thus ensuring that the operation and problems of mechanical equipment can be solved in the first time. The electronic control system includes an information processing and alarm system, which can send and feedback the problem signal in time after problems occur in the equipment. It provides an important reference for the maintenance work of maintenance personnel.

The application of mechanical and electrical technology has effectively improved the accuracy of operation. Through mechanical and electrical integration technology, the fixed operation mode can be set during the use of related mechanical equipment. The existence of this operation mode enables related machinery to achieve good cooperation and coordination, and finally forms a relatively fixed operation sequence and standard. In the operation process, this operation mode of mechanical equipment is basically not affected by various external factors, which ensures the efficiency of municipal construction. In municipal highway engineering, asphalt concrete pavement is the most common pavement form, and relevant engineering units 
will apply advanced asphalt mixing equipment to ensure the quality of asphalt mixture. In this equipment, powder supply system and asphalt system are important components, and mechanical and electrical technology plays an important role in the whole operation process of the system. The air pipe realizes the effective connection between the powder supply system and the air compressor. The connection between the weighing module and the PLC control system enables the relevant constructors to use the system to realize the scientific control of the raw material supply in the municipal construction process. As the quality of powder is relatively light, the application of air compressor can realize blowing treatment. During the use of asphalt and heat transfer oil system, PLC control system can realize scientific control of asphalt mixture temperature.

Drying system and cold material system are important components of asphalt mixing plant. The application of mechanical and electrical integration technology can realize scientific control of this system. For example, a certain supporting structure is often set between the rim and the drying drum. The existence of this structure makes the distance between the rim and the drying drum still maintain a relatively stable state even after the drying drum expands with heat and shrinks with cold, thus ensuring the stable and reliable operation of the system. The mechanical and electrical technology in the drying system realizes the combination of high-pressure spray and low-pressure airflow. In the cold material supply system, the application of mechanical and electrical technology has realized the scientific control of the feeding amount. In municipal engineering construction, the application of mechanical and electrical technology is not only reflected in the adjustment and improvement of related machinery, but also can realize the automation of some construction links in the construction process. For example, in some construction links, the relevant construction personnel can fully apply the mechanical electronic control technology to realize automatic control, so that multiple mechanical equipment can achieve good cooperation in this control system to realize the automation of operation flow. In recent years, with the development and progress of technology, mechanical and electrical technology has been gradually applied in many fields. For example, in municipal engineering construction, the application of mechanical and electrical technology and equipment has improved the efficiency of municipal construction. In addition, the quality of work can conform to the use standard of municipal engineering. It also improves the infrastructure of the city and promotes the rapid development of the city.

\subsection{Establish information management system}

The application of information management system in municipal engineering can effectively promote the work efficiency of mechanical and electrical installation, and strengthen the monitoring and supervision of each installation operation link. In the current municipal engineering field, the application of information technology can promote the development of enterprises to modern engineering construction enterprises. Using information system can manage the installation progress of mechanical and electrical equipment scientifically, and can also make the installation progress plan of mechanical and electrical equipment in the system. The materials, human resource and capital needed for the whole installation project are summarized on the system, and a scientific construction plan is formed through the powerful calculation function of the system. At the same time, the managers of mechanical and electrical installation projects can control the overall installation progress through the information system. Besides, the personnel of each department of the enterprise can realize the management and control of mechanical and electrical equipment installation projects by using the data provided by the information system. The financial personnel can analyze the installation cost of mechanical and electrical equipment, while the personnel of the quality management department can strengthen the supervision and monitoring of the installation operation of mechanical and electrical equipment through the data gathered by the information system. In the process of mechanical and electrical installation of municipal engineering, it is necessary to establish a management system of project manager responsibility system, and assign reasonable management authority to each mechanical and electrical equipment installers in each project, so as to ensure the close cooperation and communication of each personnel and promote the 
smooth development of the whole mechanical and electrical installation operation.

\section{Conclusion}

The installation and construction of mechanical and electrical equipment in municipal engineering is an important part of the whole project. In the installation and construction, with a scientific and rigorous, serious and pragmatic attitude, companies should pay attention to equipment supervision, promote quality management, standardize project acceptance, and strictly meet the requirements before, during and after the installation and construction, so as to achieve high technical standards. Overall innovative management ideas and implementation capabilities are also needed to give full play to the due role of mechanical and electrical equipment in municipal engineering.

\section{References}

1. Chen Y. Discussion on construction site management strategy of municipal bridge engineering (in Chinese). Home 2020; (11); $101+111$.

2. Pang F. Analysis on the relationship among municipal engineering quality, schedule and cost management (in Chinese). Home Ownership 2020; (11); 125.

3. Tursun N. Thinking experience of rural land transfer system reform and urban and rural planning in China (in Chinese). Southern Agricultural Machinery 2020; 51(7): 82. 